\title{
Pessimism, Reflective Planning, Self-Handicapping, Health Behaviors and Depressed Mood in Taiwanese Young Adults
}

\author{
Wan-Lan Chen ${ }^{1,2}$, Ke-Ni Kao ${ }^{3}$ \\ ${ }^{1}$ Department of Human Development and Psychology, Tzu Chi University, Taiwan \\ ${ }^{2}$ Psychiatric Department, Buddhist Tzu Chi General Hospital, Adjunct Clinical Psychologist, Hualien, Taiwan \\ ${ }^{3}$ Division of Orthopedic Rehabilitation, Mennonite Christian Hospital, Clinical Psychologist, Hualien, Taiwan \\ Email: wanlanchen@mail.tcu.edu.tw
}

How to cite this paper: Chen, W.-L., \& Kao, K.-N. (2018). Pessimism, Reflective Planning, Self-Handicapping, Health Behaviors and Depressed Mood in Taiwanese Young Adults. Psychology, 9, 2752-2767. https://doi.org/10.4236/psych.2018.913158

Received: October 23, 2018

Accepted: December 7, 2018

Published: December 10, 2018

Copyright $\odot 2018$ by authors and Scientific Research Publishing Inc. This work is licensed under the Creative Commons Attribution International License (CC BY 4.0).

http://creativecommons.org/licenses/by/4.0/

c) (i) Open Access

\begin{abstract}
Extensive research supports that pessimism leads to negative effects on health and emotions. However, there is also evidence indicating that some forms of pessimism may be adaptive for adjustment. The present study investigates the effects of pessimistic trait, reflective planning and self-handicapping on individuals' health behavior and depressive mood. The samples comprised 322 Taiwanese young adults. Structural equation modeling analyses indicated that pessimists adopting reflective planning as coping were more likely to engage in health-promoting behaviors and report lower depressed mood. In contrast, pessimists adopting self-handicapping as coping were tended to engage in fewer health behaviors and report higher depressed mood. These data are interpreted as evidence that pessimism has the potential for leading to use either reflective planning or self-handicapping as coping strategies, and that the two strategies are related to different behavioral and psychological consequences. Richer understanding of the interactive effects of pessimism and coping strategies on health-related outcomes requires more objective measurement and longitudinal research design.
\end{abstract}

\section{Keywords}

Pessimism, Reflective Planning, Self-Handicapping, Health Behavior, Depressed Mood

\section{Introduction}

Pessimism/optimism is a commonly discussed psychological theme among scholars. Research on health psychology has demonstrated that optimistic individuals 
(e.g. a person who tends to look on the bright side or have positive expectations for upcoming events) are likely to have more favorable health outcomes (Kivimäki et al., 2005; Peterson, 2000), higher levels of life satisfaction (Schöllgen, Huxhold, Schüz, \& Tesch-Römer, 2011), and better quality of life (Bailey, Eng, Frisch, \& Snyder, 2007). By contrast, pessimistic individuals (e.g. a person who has negative expectations for upcoming events or tends to see the miserable and dark aspects of life) have more physical symptoms (Nabi et al., 2010) and are more likely to experience negative emotions (Chang \& Lawrence, 2001).

However, cross-cultural studies have identified that particular values prevalent among East Asian cultures, such as "be prepared for danger in times of peace" "save for a rainy day" and the cautionary "Sorrow follows pleasure," encourage individuals to hold negative expectations of events that have yet to occur and to prepare for the worst. Chang (1996) noted that Asian Americans tended to be more pessimistic than White Americans, although no differences were found regarding levels of optimism. Furthermore, pessimistic White Americans tended to cope stress in a passive fashion, whereas pessimistic Asian Americans were inclined to adopt active coping strategies under stress. Chang's results indicated that personality traits per se may not predict certain behaviors or performance, other factors such as cultural background and situational context must also be considered. However Chang's study on the different coping style of pessimists between Asians and other ethnic groups was limited to American. More researches are needed to examine whether individuals with pessimistic tendency in East Asia also use active coping as do pessimistic Asian in America.

Research reviewing personality traits and coping strategies has mostly focused on short-term behavioral performance (e.g., academic or cognitive task performance) as an indicator for outcome measurement (Martin, Marsh, \& Debus, 2001; Norem \& Cantor, 1986a,1986b; Norem \& Illingworth, 2004). However, the effects of personality traits and coping on long-term behavior patterns (e.g., health behaviors) remain unclear. The relationship between pessimism, coping and their association with health behaviors and psychological health needs further investigation, especially in young adults. The transition from young adulthood to middle age is characterized by increased responsibilities, such as forming self-identities, making career decision, and achieving financial independence. To what extent that their level of pessimism and the way of coping influence their health behavior and subsequent depression need to be tested empirically. The purpose of the study was to investigate the cross-sectional association between pessimistic trait, coping strategies, health behaviors, and depressed mood of young adults in Taiwan.

\section{Reflective Planning vs. Self-Handicapping}

Norem and Cantor (1986a) first noted that certain pessimists set extremely low expectation for and felt anxious about upcoming events, meanwhile, they proactively cope with the potential failure by working hard to avoid that failure. Those high pessimistic individuals often rehearsed the least desirable scenario in their 
mind, and then they transformed the resultant anxiety into a motive that forces them to proactively prepare to avoid the occurrence of negative outcome (Norem \& Illingworth, 2004). Reflecting on possible negative consequences and planning for the action are key components of coping strategy employed by some pessimists.

Showers and Ruben (1990) were interested in whether the reflection of pessimists was similar to the rumination of depressed people. The results showed that when facing immediate stressful situations, both pessimists and depressed people felt anxious and hold negative expectations. In contrast to individuals with depressive tendencies chose avoidance as their coping strategy, reflective pessimists proactively prepared for the upcoming events, after the stress eased, the anxiety level among reflective pessimists reduced, whereas their depressed counterparts dwelt on certain details of the experience and experienced residual anxiety.

Nevertheless, not all pessimists proactively prepare for the coming events to avoid negative results. Indeed, negative expectations or anxiety may ultimately "entrap" individuals and incapacitate them (Eronen, Nurmi, \& Salmela-Aro, 1998; Martin, Marsh, \& Debus, 200). Pessimists may assume that the future is full of difficulties and choose to take actions that impede their chances of success. Although such actions increase the possibility of failure, individuals can at least ascribe the failure to external obstacles instead of their own underperformance (Berglas \& Jones, 1978).

Berglas and Jones (1978) named these behavioral pattern as self-handicapping which involves any behavior or choice that externalizes failures (i.e., finding excuses for failings) and internalizes successes (i.e., accepting credit for achievements). Ross, Canada, and Rausch (2002) noted that people reporting high negative affect and low planning capacity tended to adopt self-handicapping behaviors. Rastegar, Afshari, Seif, and Jahromi (2012) also found that individuals with high levels of anxiety and sense of insecurity were afraid of receiving negative feedback when faced with stressful situations. Consequently, they tended to avoid such stressful situations by employing self-handicapping strategies.

Self-handicapping is related to but different from an individual's attribution process. The former is a prospective strategy that results in behaviors that impede performance before an event occurs, whereas attribution refers to an individual's explanations for results after an event. Therefore, self-handicapping serves as the basis of attribution, but is not the same as attribution itself (Urdan \& Midgley, 2001).

Although self-handicapping and reflective planning are both self-defensive strategies (Martin et al., 2003) derived from a fear of failure (Elliot \& Church, 2003; Norem, 2008), the two are clearly different. Employing self-handicapping strategies, such as procrastinating or finding excuses for failure, can decrease threats to self-esteem; however, long-term use of such strategies may have a negative effect on individuals' achievements and mental health (Urdan \& Midgley, 2001; Zuckerman et al., 1998). By contrast, although reflective planners manage 
their anxiety through setting lower expectations, they proactively prepare themselves to avoid failure. Because of their distinct coping approaches, these two strategies may result in different effects despite sharing a similar basis.

\section{Pessimism, Reflective Planning, Self-Handicapping, and Health Behaviors}

Among studies exploring the coping strategies adopted by pessimists, the majority have evaluated their effects by examining academic efficacy or achievement (Martin et al., 2001; Norem \& Cantor, 1986; Norem \& Illingworth, 2004; Zuckerman et al., 1998). Only limited evidence available suggests there may be a relationship between coping strategies and health related outcome in people high on pessimism. Chang and Sivam (2004) observed a positive correlation between fears related to severe acute respiratory syndrome (SARS) and reflective planning, and they found that people with higher levels of SARS-related fear and higher scores on reflection tended to transform their SARS-related fears into proactive actions. For example, such individuals may avoid going to large crowds during influenza pandemic, or they would wear gauze masks when visiting hospitals; these healthy habits are considered to provide individuals from disease. Norem and Crandall (1991) noted that, compared with optimists, high reflective planning pessimists were more concerned about their health; therefore, they sought disease-related information and took direct actions for health promotion.

Vollrath and Torgersen (2008) also found that individuals with high degrees of anxiety and negative thinking were less likely to engage in harmful habits such as smoking or illegal substance use if they adopted proactive coping strategies (e.g., problem solving). Conversely, individuals with the same characteristics were prone to substance use when they reported lower scores on organization skills. Additionally, such people reported to use more alcohol or other substances (Zuckerman \& Tsai, 2005). Similarly, Auerbach, Abela, and Ho (2007) found that negative thinking and highly anxious individuals with low problem-solving capacity and less target-oriented motives were more likely to engage in risky behaviors such as excessive drinking, self-harm, and substance use to cope with their depressed mood or anxiety.

From the aforementioned studies, reflectivity helps pessimists to implement preventive measures, providing great short-term efficacy. However, whether reflectivity provides the same positive effects for long-term habits is still unknown, along with whether self-handicappers engage in fewer health-promoting behaviors than other individuals because they fear failure. Research concerning health behaviors has yet to focus on the effects of individual personality traits and coping strategies on such behaviors.

The present study will examine the following research questions:

1) Is pessimism associated with reflective planning? If so, does the association have any effects on health behavior and depressed mood? On the basis of prior 
research, we expect that the association between pessimism and reflective planning would have a significant effect on health behaviors and depressed mood.

2) Is pessimism associated with self-handicapping? If so, does the association have any effects on health behavior and depressed mood? On the basis of prior research, we expect that the association between pessimism and self-handicapping planning would have a significant effect on health behaviors and depressed mood.

\section{Methods}

\section{Procedures and Participants}

A total of 322 participants provided data for the present study. Of the total sample, 120 were men $(37.3 \%)$ and 202 were women (62.7\%), with an average age of 25.16 years $(\mathrm{SD}=2.42)$. The majority of the respondents had college-level of education (55.3\%), and approximately one third of the sample was composed of students (36.6\%). Forty-six percent of the participants were employed full time, $18 \%$ were not employed outside the home.

Data were collected through an online questionnaire linked to several social networking sites, including Facebook psychology club and psychology blogs. Eligible participants for this study were between 20 - 30 years old and with no critical illness for the last five years. Once they confirmed that they met the criteria for participation, they were asked to read the consent form and consent to participate. They were then taken to the questionnaires. The questionnaires were translated from English to Chinese through three-procedure approach suggested by Brislin (1970). The English inventories were first translated by the both authors into Chinese, and the Chinese inventory was then back-translated into English by a native English speaker. The authors compared the back-translation version with the original ones and revised the Chinese inventories as required. Three graduate students were asked to fill out both Chinese and English inventories, further revision was made if inconsistent responses were found between the two versions of the same inventory. This research was approved by the Research Ethics Committee of National Taiwan University (NTU-REC No.: 201212HS001).

\section{Measures}

\subsection{Pessimistic Traits and Reflective Planning}

We measured pessimistic traits and reflective by using the revised DPQ developed by Norem (2001). The DPQ comprises 12 items with pessimism and reflectivity subscales. The pessimism subscale contained 4 items including "sometimes I worry that I won't be able to carry through my intentions when I'm preparing for an important situation" and "when I'm preparing for an important situation, I often start out expecting the worst, even though I will probably do okay."

The reflective planning subscale was composed of 8 items including "before preparing for an important situation, I carefully consider all possible outcomes" 
and "when I'm preparing for an important situation, considering what can go wrong helps me to prepare." Scoring was performed using a 7-point Likert scale ranging from 1 (not true at all of me) to 7 (very true of me). A high score indicated higher frequency of adopting reflective planning. The Cronbach's alphas (i.e., internal consistency) of the DPQ, pessimism subscale, and reflectivity subscale were $.78, .79$, and .73 , respectively, with a test-retest reliability of .73 . Research has shown that DPQ has favorable predictive validity (Norem, 2001).

\subsection{Self-Handicapping}

By employing the self-handicapping scale (SHS) developed by Jones and Rhodewalt (1982), we measured the tendency of the participants to use self-handicapping strategies in situations where their performance was being evaluated. The SHS comprises 24 items with two subscales, namely the behavioral self-handicapping subscale (12 items) and self-reported handicapping subscale (12 items). However, we only adopted the behavioral subscale for this research, with items including "I tend to put things off to the last moment," "I try not to get too intensely involved in competitive activities so it won't hurt too much if I lose or do poorly," and "when something important is coming up, such as an exam or a job interview, I try to get as much sleep as possible the night before." Scoring was performed using a 6-point Likert scale ranging from 0 (disagree very much) to 5 (agree very much). Rhodewalt, Saltzman, and Wittmer (1984) reported the internal consistency reliability of the SHS was .78 with a test-retest reliability of .74 (time interval = 1 month). Rhodewalt (1994) demonstrated that the SHS possesses favorable predictive validity.

\subsection{Health Behaviors}

We used the Chinese Health Promoting Lifestyle Profile (HPLP) developed by Wei and $\mathrm{Lu}$ (2005) to assess the healthiness of the participants' lifestyles. The Chinese HPLP-S contains 24 items with six subscales, namely self-actualization (e.g., "work toward long-term goals in my life"), health responsibility (e.g., "have my blood pressure checked and know what it is"), physical activity (e.g., "do stretching exercises at least three times per week"), nutrition (e.g., "regularly eat three meals per day"), interpersonal support (e.g., "spend some time with close friends"), and stress management (e.g., "relax my muscles before sleep"). Each subscale comprised 4 items and was scored using a 4-point Likert scale from 1 (never) to 4 (routinely). When a participant's total score was high, the individual was likely to have a healthy lifestyle. The internal consistency of the Chinese HPLP-S was .90, with the subscales ranging from .63- .79 .

\subsection{Depressed Mood}

This study adopted depressed mood as the indicator for the participants' psychological health, which was evaluated by Taiwanese Depression Questionnaire (TDQ; Lee, Yang, Lai, Chiu, \& Chou, 2000). The TDQ comprises 18 items, with 
participants answering items describing their perceptions of their physical and emotional state. Items in the TDQ include "I sleep badly," "I feel annoyed," and "I am tired of everything." Scoring was performed using a 4-point Likert scale to measure the frequency of the described feeling over the preceding week, ranging from 0 (never/ seldom [i.e., less than one day]) to 3 (routinely [5 - 7 days]). A high overall score indicated a high level of depression, with a score over 19 indicating increased depressive tendencies. This questionnaire has been shown to have favorable reliability and validity (Li et al., 2000).

\section{Results}

\subsection{Descriptive Statistics}

Prior to assessing the study hypotheses, potential confounding variables were examined. A series of independent samples $t$ test was conducted to test gender differences on study variables. The results showed no significant gender differences on pessimistic traits, reflective planning, self-handicapping, health behaviors, and depressed mood. The inter-correlations of participants' age and study variables were calculated. The results revealed that only a weak correlation was discovered between age and depressed mood $(r=-.12 ; p<.05)$, with the older participants exhibiting lower scores for depressed mood. Thus, age was included as a control variable in the subsequent structure modeling analysis.

Descriptive statistics of study variables are presented in Table 1. Participants with high degrees of pessimism were more likely than low pessimists to employ reflective planning and self-handicapping strategies. Moreover, participants who scored higher on depressed mood tended to have lower scores on the following

Table 1. Means, standard deviations, and coefficients of all the variables.

\begin{tabular}{|c|c|c|c|c|c|c|c|c|c|c|}
\hline Variable & 1 & 2 & 3 & 4 & 5 & 6 & 7 & 8 & 9 & 10 \\
\hline \multicolumn{11}{|l|}{ 1. PT } \\
\hline 2. RP & $.39^{\star *}$ & & & & & & & & & \\
\hline 3. $\mathrm{SH}$ & $.46^{* *}$ & $-.55^{* *}$ & & & & & & & & \\
\hline 4. SA & $-.27^{\star *}$ & $.37^{* *}$ & $-.45^{\star *}$ & & & & & & & \\
\hline 5. HR & -.09 & .02 & -.02 & $.52^{\star *}$ & & & & & & \\
\hline 6. IS & $-.16^{* *}$ & $.19^{*}$ & $-.25^{* *}$ & $.53^{* *}$ & $.39^{* *}$ & & & & & \\
\hline 7. SM & -.14 & $.15^{*}$ & $-.25^{* *}$ & $.45^{\star *}$ & $.53^{* *}$ & $.49^{* *}$ & & & & \\
\hline 8. $\mathrm{Nu}$ & $-.19^{*}$ & $.22^{* *}$ & $-.28^{* *}$ & $.47^{\star *}$ & $.53^{* *}$ & $.41^{\star *}$ & $.49^{* *}$ & & & \\
\hline 9. PA & $-.19^{*}$ & $.20^{\star}$ & $-.25^{\star *}$ & $.27^{\star *}$ & $.50^{\star *}$ & $.39^{* *}$ & $.53^{\star *}$ & $.53^{* *}$ & & \\
\hline 10. DM & $.45^{* *}$ & $-.54^{\star *}$ & $.56^{* *}$ & $-.27^{\star *}$ & $-.32^{\star *}$ & $-.22^{\star *}$ & $-.34^{\star *}$ & $-.28^{\star *}$ & $-.32^{\star *}$ & \\
\hline $\begin{array}{c}\text { Mean } \\
\text { SD }\end{array}$ & $\begin{array}{l}13.46 \\
(3.25)\end{array}$ & $\begin{array}{l}12.74 \\
(4.40)\end{array}$ & $\begin{array}{l}29.97 \\
(9.28)\end{array}$ & $\begin{array}{l}11.56 \\
(2 / 54)\end{array}$ & $\begin{array}{c}8.85 \\
(2.38)\end{array}$ & $\begin{array}{l}11.94 \\
(2.42)\end{array}$ & $\begin{array}{l}10.54 \\
(2.15)\end{array}$ & $\begin{array}{l}10.13 \\
(2.21)\end{array}$ & $\begin{array}{c}8.85 \\
(2.38)\end{array}$ & $\begin{array}{c}12.93 \\
(9.60)\end{array}$ \\
\hline
\end{tabular}

${ }^{\star} p<.05,{ }^{*} p<.01$. PT, pessimistic traits; $\mathrm{RP}$, reflective planning; $\mathrm{SH}$, self-handicapping; SA, self-actualization; $\mathrm{HR}$, health responsibility; IS, interpersonal support; SM, stress management; $\mathrm{Nu}$, nutrition; PA, physical activity; DM, depressed mood. 
health behaviors, self-actualization, interpersonal support, exercise, and nutrition awareness. The participants who scored higher on reflective planning had less depressed moods, and engaged more health behaviors. Participants with higher levels of self-handicapping experienced more depressed moods. Significant negative correlations were discovered between self-handicapping and all health behaviors except for health responsibility. All the health behavior subscales were significantly and negatively correlated with depressed mood.

\subsection{Structural Equation Modeling of Pessimism, Coping Strategies, Health Behaviors, and Depressed Mood}

Two hypothetical models were proposed to explore the effects of pessimistic traits on health behaviors and depressed mood through coping strategies. In these two models, the pessimistic traits of the participants were the exogenous variables; the coping strategies (i.e., reflective planning and self-handicapping) and health behaviors were the mediators; and depressed mood was the outcome variable. A two-step approach was implemented (Anderson \& Gerbing, 1988) to verify whether the sample data matched the hypothesized models. In the first step, a confirmatory factor analysis was conducted to measure the stability among latent variables and the model fit. During the second step, we tested the structural models. All the latent variable models were analyzed using SPSS Amos 22.0 software with maximum likelihood estimation.

The models' goodness of fit (GIF) was measured according to the criteria for fit indices suggested by Hu and Bentler (1999) as follows: 1) A significant $\chi^{2}$ indicates poor fit between the hypothesized model and sample data. However, $\chi^{2}$ (i.e., chi square) is often overestimated when the sample size is large. Thus, a desirable GIF is found when the chi square-degrees of freedom $\left(\chi^{2} / \mathrm{df}\right)$ ratio of the tested model is less than 3 (Kline, 2005). 2) The comparative fit index (CFI) identifies the extent to which a research model is different from an alternative uncorrelated model; a CFI greater than .95, suggests a desirable GIF. 3) The root mean square error of approximation (RMSEA) is used to compare the difference between the research model and model with perfect fit. The cutoff value should be .06 , and the level of fit is higher when the RMSEA is low. 4) The standardized root mean square residual (SRMR) represents the standardized difference between the prediction correlation and observed correlation. A lower SRMR value indicates that a model fits its observations; the cutoff value of SRMR should be .08 .

We also tested whether an alternative model could replace the current model based on suggestions provided by Burnham and Anderson (1998). When the potential model was a nested model, the structure was simpler than the current model. The $\Delta \chi^{2}$ of the chi-square test was considered the index. The current research model was retained when $\Delta \chi^{2}$ reached significance. A nonsignificant $\Delta \chi^{2}$ implied no difference existed between the two models; if so, the simpler model was more favorable. 


\subsection{Confirmatory Factor Analysis of the Latent Variables and Measurement Model}

The measurement index of pessimistic traits was the total score of the 4 items in the pessimism subscale. The latent variables with unidimensional measurement index (i.e., reflective planning, self-handicapping, and depressed mood) were estimated using the item parceling technique (Russell, Kahn, Spoth, \& Altmaier, 1998). The item-to-construct loading were ranked from the highest to the lowest, and then distributed evenly to three item parcels for greater consistency of variance. Regarding the reflective planning subscale (8 items in total), Parcels A and $B$ each comprised 3 items, whereas Parcel C contained 2 items. For the self-handicapping subscale (12 items), Parcels A, B, and C each had 4 items. For the depressed mood subscale (18 items), Parcels A, B, and C each contained 6 items. The measurement indices of the health behaviors were the scores of its six subscales, namely self-actualization, health responsibility, interpersonal support, stress management, physical activity, and nutrition.

The results of confirmatory factor analysis for the latent variables (i.e., reflectivity, self-handicapping, and depressed mood) revealed that the composite reliability among the latent variables was higher than the cutoff of .70 suggested in Bagozzi and Yi (1988), indicating acceptable convergent validity. In addition, confirmatory factor analysis for health behaviors determined that the settings of the measurement model delivered an ideal fit $\left[\chi^{2}(9, N=322)=33.97 ; p<.00\right.$; CFI $=.96$; RMESA $=.07 ;$ SRMR $=.04)]$. The factor loadings of these six measurement indices were statistically significant with standardized factor loadings ranging from .52 to .75 .

Confirmatory factor analysis was separately conducted on the measurement models of reflective planning and self-handicapping. Each measurement model comprised three latent variables and one measurement variable, and there were 13 observation indices. The results of the GIF test revealed acceptable fit between the data and reflectivity model $\left[\left(\chi^{2}(60 ; N=322)=141.17 ; p<.00 ; \chi^{2} / \mathrm{df}=2.35\right.\right.$; CFI $=.96 ;$ RMSEA $=.07 ; \operatorname{SRMR}=.07]$ as well as between the data and self-handicapping model $\left[\chi^{2}(60 ; N=322)=147.67 ; p<.00 ; \chi^{2} / \mathrm{df}=2.46 ; \mathrm{CFI}\right.$ $=.96 ; \mathrm{RMSEA}=.06 ; \mathrm{SRMR}=.07]$. Correlations among the variables within these two models were significant.

\subsection{Structural Model Analysis}

The results of measurement model analysis demonstrated a significant correlation between the measurement and latent variables, and between all the latent variables. Additionally, these models showed good model fits; thus, we proceeded to conduct structural model analysis.

According to the two hypotheses of this study, pessimistic traits directly correlate with depressed mood and affect depressed mood through reflective planning (Hypothesis Model I) and self-handicapping (Hypothesis Model II). Both reflective planning and self-handicapping directly affect depressed moods, and 
they also affect depressed mood through health behaviors. Age was also included as a controlled variable for depressed mood. Structural model analysis demonstrated that the model for reflective planning $\left[\chi^{2}(72 ; N=322)=173.97 ; p<.00\right.$; $\chi^{2} / \mathrm{df}=2.42$; CFI $=.96 ;$ RMSEA $=.07$; SRMR $\left.=.06\right]$ and self-handicapping $\left[\chi^{2}\right.$ $(72 ; N=322)=176.82 ; p<.00 ; \chi^{2} / \mathrm{df}=2.46 ; \mathrm{CFI}=.96$; RMSEA $=.07$; SRMR $=.07]$ were both acceptable. However, the path coefficients between pessimistic traits and health behaviors and between pessimistic traits and depressed mood were not statistically significant. Therefore, we performed a parsimonious analysis (models I-A and II-A), with the nonsignificant paths excluded.

Indices for structural model fit indicated an ideal GIF between the parsimonious models and data. Although the GIF of model I-A $\left[\chi^{2}(74 ; N=322)=\right.$ $175.71 ; p<.00 ; \chi^{2} / \mathrm{df}=2.37$; CFI $=.96$; RMSEA $=.07$; SRMR $\left.=.07\right]$ was not different from that of model I $\left[\Delta \chi^{2}(2, N=322)=1.74 ; p>.05\right]$, model I-A was simpler. Similarly, although no difference was detected between the GIF of model II-A $\left[\chi^{2}(74 ; N=322)=181.81 ; p<.00 ; \chi^{2} / \mathrm{df}=2.46\right.$; CFI = .96; RMSEA = .07; SRMR $=.07]$ and that of model II $\left[\Delta \chi^{2}(2, N=322)=4.99 ; p>.05\right]$, model II-A was simpler. Therefore, models I-A and II-A were more desirable than models I and II. Figure 1 and Figure 2 present the standardized coefficients of all the variables. Except for the direct effect of pessimistic traits on depressed mood and on health behaviors, the other hypothesized relationships reached significant levels.

This study adopted bootstrapping to verify the significance of mediation in the structural models (Mackinnon, Lockwood, Hoffman, West, \& Sheets, 2002). Samples from the original data were repeatedly drawn 1000 times for parameter estimation and inference. When the $95 \%$ bias-corrected confidence interval

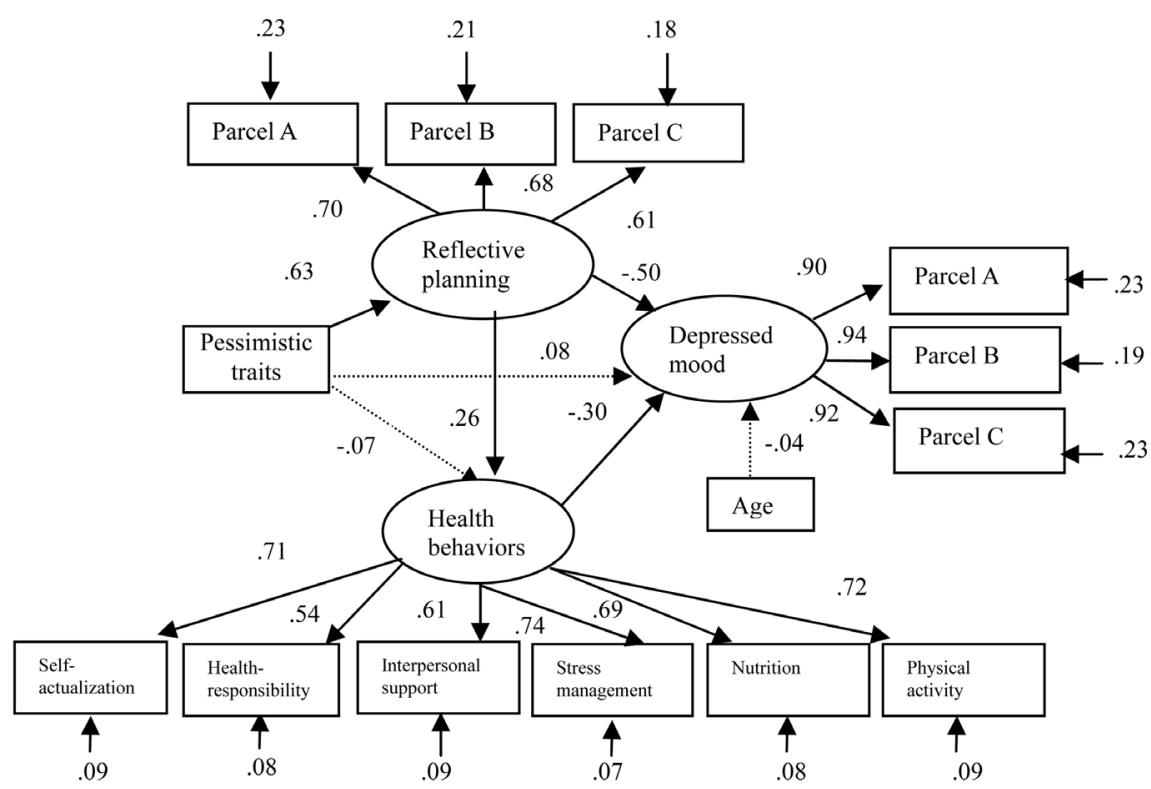

Figure 1. Hypothetical model (model I-A) of pessimistic traits, self-handicapping, health behaviors, and depressed mood. ${ }^{\star}$ Note: Numbers refer to standardized path coefficients (beta). 


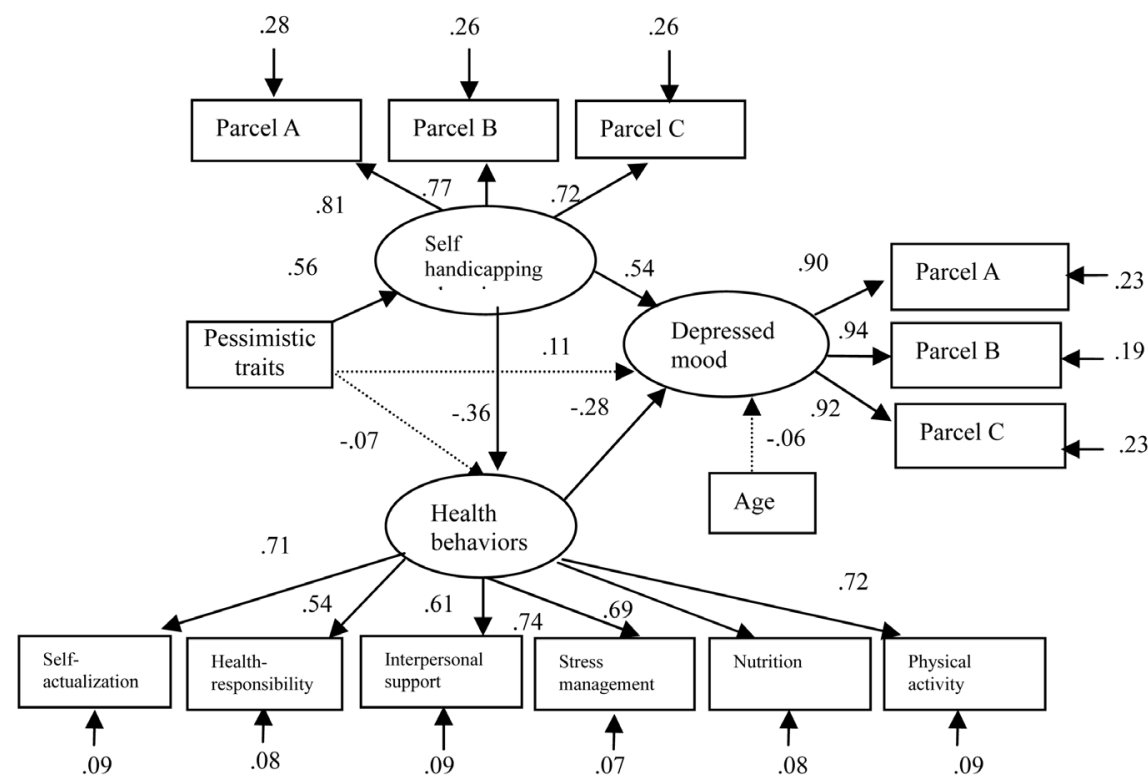

Figure 2. Hypothetical model (model II-A) of pessimistic traits, reflective planning, health behaviors, and depressed mood. ${ }^{\star}$ Note: Numbers refer to standardized path coefficients (beta).

( $95 \%$ CI) did not contain zero, a significance of mediation was determined. The bootstrapping results in model I-A were as follows: the mediation of pessimistic traits on depressed mood through reflectivity and health behaviors was significant $(\beta=.43$; $\mathrm{SE}=.04 ; 95 \% \mathrm{CI}=.34, .49)$; that of pessimistic traits on health behaviors through reflectivity was significant $(\beta=-.23$; $\mathrm{SE}=.05 ; 95 \% \mathrm{CI}=-.32$, -.14); that of pessimistic traits on depressed mood through self-handicapping and health behaviors was significant $(\beta=.38$; $\mathrm{SE}=.04 ; 95 \% \mathrm{CI}=.28, .44)$; that of pessimistic traits on health behaviors through self-handicapping was significant $(\beta=-.21 ; \mathrm{SE}=.04 ; 95 \% \mathrm{CI}=-.30,-.12)$; and that of self-handicapping on depressed mood through health behaviors was significant $(\beta=.10$; $\mathrm{SE}=.03 ; 95 \%$ $\mathrm{CI}=.06, .15)$.

\section{Discussion}

This study investigated the direct and indirect pattern of association between pessimistic trait and coping style in relation to different outcome measures. Our results indicated that pessimists adopting reflective planning as coping were likely to engage in health-promoting behaviors (e.g., regular exercise, stress relief, and balanced nutrition intake), which further served to protect their psychological health, namely they had lower depressed mood. Our results agree with the findings of previous studies (e.g., Eronen et al., 1998; Schreuder et al., 2012; Wang \& Miao, 2009). The results of Schreuder et al. (2012) indicated that individuals who proactively employed coping strategies, such as pondering over problems or developing different solutions, tended to report more favorable physical and mental health. Wang and Miao (2009) found that medical students 
who implemented adaptive strategies such as taking steps of problem-solving or seeking interpersonal support had higher physical as well as mental health than those adopting self-accusation or avoidance coping. Additionally, the findings of Chang and Sivam (2004) and Norem and Crandall (1991) agree that reflective pessimists are more likely to engage in health-promoting or risk-preventing behaviors. In sum, our results showed that when pessimists adopt reflective planning to transform anxiety into actual actions, which enable them to plan in advance and avoid negative consequences.

Our hypothesis regarding the influence of pessimism through self-handicapping in relation to health behavior and depressed mood was also confirmed. Individuals reported high level of pessimism were associated higher self-handicapping, which in turn was associated with fewer health behaviors and higher depressed mood. This result was consistent with the previous findings (Compas, Connor-Smith, Saltzman, Thomsen, \& Wadsworth, 2001; Sahranç, 2011; Smith, Sinclair, \& Chapman, 2002; Zuckerman et al., 1998). Longitudinal research also indicates that, self-handicappers that have more negative emotions, are less involved in health-promoting behaviors, and engage in risky behaviors that threaten their health, including the use of substances (Zuckerman \& Tsai, 2005). Moreover, the relationship between self-handicapping and social adjustment has revealed that self-handicapping is associated with increased use of healthcare services. This may not only be because self-handicappers tend to have poor health, but also because they look for concrete proofs (e.g. medical certificates) to backup their excuses for failure (Zuckerman et al., 1998).

Taken together, the current results suggest that different coping strategies result in different effects on health behaviors and mental health. When pessimists adopt reflective planning as a coping strategy for health issues, they probably anticipate a variety of negative health outcomes would occur, meanwhile they have plans prepared to address their concerns. By contrast, when pessimists choose self-handicapping to cope with health-related concerns, they are likely to struggle with behaviors that require commitment to improve health (e.g., regular exercise or eating well). Self-handicappers also seek excuses to prevent themselves from engaging in healthy lifestyles, which in turn are associated with lower physical and mental health.

Despite important insights have been gained in the present study, certain limitations and direction for future research deserve attention. First, the current study exclusively relied on self-report measures, therefore future studies should consider physiological measurements, observe-based or behavioral indicators to evaluate health behavior and coping strategies. Second, the study did not include middle-aged or elderly participants, hence the sample is limited in generalizability. Future study could benefit from recruiting participants with wide range of ages. Third, we did not investigate other personality traits, such as optimism or neuroticism, which may also be mediated through coping strategies to have influence on health behaviors or affect. Therefore, further efforts with the use of 
various personality measures may provide more evidence of individual differences and coping. Finally, the cross-sectional design limits the causal inferences drawn from the data. It is plausible that reciprocal causality between research variables also exist. Further research with longitudinal studies is needed to address this question.

With respect to the implication of the current study, the findings may offer a direction for clinical practice. Interventions aimed at promoting reflection planning and decreasing self-handicapping should be one of the treatment goals for clients with pessimistic traits. By learning to ponder over the problems and develop different solutions, pessimists are likely to feel greater senses in control, which in turn may motivate them to take appropriate actions dealing with difficult situations.

\section{Conflicts of Interest}

The authors declare no conflicts of interest regarding the publication of this paper.

\section{References}

Anderson, J., \& Gerbing, D. (1988). Structural Equation Modeling in Practice: A Review and Recommended Two-Step Approach. Psychological Bulletin, 103, 411-423. https://doi.org/10.1037/0033-2909.103.3.411

Auerbach, R. P., Abela, J. R. Z., \& Ho, M. H. R. (2007). Responding to Symptoms of Depression and Anxiety: Emotion Regulation, Neuroticism, and Engagement in Risky Behaviors. Behaviour Research and Therapy, 45, 2182-2191. https://doi.org/10.1016/j.brat.2006.11.002

Bagozzi, R. P., \& Yi, Y. (1988). On the Evaluation of Structural Equation Models. Journal of the Academy of Marketing Science, 16, 74-94. https://doi.org/10.1007/BF02723327

Bailey, T. C., Eng, W., Frisch, M. B., \& Snyder, C. R. (2007) Hope and Optimism as Related to Life Satisfaction. The Journal of Positive Psychology, 2, 168-175. https://doi.org/10.1080/17439760701409546

Berglas, S., \& Jones, E. E. (1978). Drug Choice as a Self-Handicapping Strategy in Response to Noncontingent Success. Journal of Personality and Social Psychology, 36, 405-417. https://doi.org/10.1037/0022-3514.36.4.405

Brislin, R. W. (1970). Back-Translation for Cross-Cultural Research. Journal of Cross-Cultural Psychology, 1, 185-216. https://doi.org/10.1177/135910457000100301

Burnham, K. P., \& Anderson, D. R. (1998). Model Selection and Inference: A Practical Information-Theoretic Approach. New York: Springer-Verlag. https://doi.org/10.1007/978-1-4757-2917-7

Chang, E. C. (1996). Cultural Differences in Optimism, Pessimism, and Coping: Predictors of Subsequent Adjustment in Asian American and Caucasian American College Students. Journal of Counseling Psychology, 43, 113-123.

https://doi.org/10.1037/0022-0167.43.1.113

Chang, E. C., \& Lawrence, J. S. (2001). Optimism, Pessimism, and Positive and Negative Affectivity in Middle-Aged Adults: A Test of a Cognitive-Affective Model of Psychological Adjustment. Psychology and Aging, 16, 524-531.

https://doi.org/10.1037/0882-7974.16.3.524

Chang, W. C., \& Sivam, R. W. (2004). Constant Vigilance: Heritage Values and Reflectiv- 
ity in Coping with Severe Acute Respiratory Syndrome in Singapore. Asian Journal of Social Psychology, 7, 35-53. https://doi.org/10.1111/j.1467-839X.2004.00133.x

Compas, B. E., Connor-Smith, J. K., Saltzman, H., Thomsen, A. H., \& Wadsworth, M. (2001). Coping with Stress during Childhood and Adolescence: Progress, Problems, and Potential in Theory and Research. Psychological Bulletin, 127, 87-127. https://doi.org/10.1037/0033-2909.127.1.87

Elliot, A., \& Church, M. A. (2003) A Motivational Analysis of Reflectivity and Self-Handicapping. Journal of Personality, 71, 369-396. https://doi.org/10.1111/1467-6494.7103005

Eronen, S., Nurmi, J.-E., \& Salmela-Aro, K. (1998). Optimistic, Defensive-Pessimistic, Impulsive and Self-Handicapping Strategies in University Environments. Learning and Instruction, 8, 159-177. https://doi.org/10.1016/S0959-4752(97)00015-7

Hu, L. T., \& Bentler, P. M. (1999). Cutoff Criteria for Fit Indexes in Covariance Structure Analysis: Conventional Criteria versus New Alternatives. Structural Equation Modeling, 6, 1-55. https://doi.org/10.1080/10705519909540118

Jones, E. E., \& Rhodewah, F. (1982). The Self-Handicapping Scale. (Available from the Second Author at the Department of Psychology, University of Utah.)

Kivimäki, M., Vahtera, J., Elovainio, M., Helenius, H., Singh-Manoux, A., \& Pentti, J. (2005). Optimism and Pessimism as Predictors of Change in Health after Death or Onset of Severe Illness in Family. Health Psychology, 24, 413-442. https://doi.org/10.1037/0278-6133.24.4.413

Kline, R. B. (2005). Principles and Practice of Structural Equation Modeling (2 ${ }^{\text {nd }}$ ed.). New York: Guilford.

Lee, Y., Yang, M. J., Lai, T. J., Chiu, N. M., \& Chau, T. T. (2000). Development of the Taiwanese Depression Questionnaire. Chang Gung Medical Journal, 23, 688-694.

MacKinnon, D. P., Lockwood, C. M., Hoffman, J. M., West, S. G., \& Sheets, V. (2002). A Comparison of Methods to Test Mediation and Other Intervening Variable Effects. Psychological Methods, 7, 83-104. https://doi.org/10.1037/1082-989X.7.1.83

Martin, A. J., Marsh, H. W., \& Debus, R. L. (2001). Self-Handicapping and Reflectivity: Exploring a Model of Predictors and Outcomes from a Self-Protection Perspective. Journal of Educational Psychology, 93, 87-102. https://doi.org/10.1037/0022-0663.93.1.87

Martin, A. J., Marsh, H. W., \& Debus, R. L. (2003). Self-Handicapping and Reflectivity: A Model of Self-Protection from a Longitudinal Perspective. Contemporary Educational Psychology, 28, 1-36. https://doi.org/10.1016/S0361-476X(02)00008-5

Nabi, H., Koskenvuo, M., Singh-Manoux, A., Korkeila, J., Suominen, S., Korkeila, K., Vahtera, J., \& Kivimaki, M. (2010). Low Pessimism Protects against Stroke: The Health and Social Support (HeSSup) Prospective Cohort Study. Stroke, 41, 187-190. https://doi.org/10.1161/STROKEAHA.109.565440

Norem, J. K. (2001). Reflectivity, Optimism, and Pessimism. In E. C. Chang (Ed.), Optimism and Pessimism: Implications for Theory, Research, and Practice (pp. 77-100). Washington DC: American Psychological Association. https://doi.org/10.1037/10385-004

Norem, J. K. (2008). Reflectivity, Anxiety, and the Complexity of Evaluating Self-Regulation. Social and Personality Psychology Compass, 2, 121-134. https://doi.org/10.1111/j.1751-9004.2007.00053.x

Norem, J. K., \& Cantor, N. (1986a). Anticipatory and Post-Hoc Cushioning Strategies: Optimism and Reflectivity in "Risky" Situations. Cognitive Therapy and Research, 10, 
347-362. https://doi.org/10.1007/BF01173471

Norem, J. K., \& Cantor, N. (1986b). Reflectivity: Harnessing Anxiety as Motivation. Journal of Personality and Social Psychology, 51, 1208-1217. https://doi.org/10.1037/0022-3514.51.6.1208

Norem, J. K., \& Illingworth, K. S. S. (2004). Mood and Performance among Defensive Pessimists and Strategic Optimists. Journal of Research in Personality, 38, 351-366. https://doi.org/10.1016/j.jrp.2003.07.002

Peterson, C. (2000). Optimistic Explanatory Style and Health. In J. E. Gillham (Ed.), Laws of Life Symposia Series. The Science of Optimism and Hope: Research Essays in Honor of Martin E. P. Seligman (pp. 145-161). West Conshohocken, PA: Templeton Foundation Press.

Rastegar, A., Afshari, M., Seif, M. H., \& Jahromi, R. G. (2012). Investigating the Intermediate Role of Achievement Goals among Personality Traits and Educational Self-Handicapping among Payam-e-Noor University Students. Journal of American Science, 8, 353-357.

Rhodewalt, F. (1994). Conceptions of Ability, Achievement Goals, and Individual Differences in Self-Handicapping Behavior: On the Application of Implicit Theories. Journal of Personality, 62, 67-85. https://doi.org/10.1111/j.1467-6494.1994.tb00795.x

Rhodewalt, F., Saltzman, A. T., \& Wittmer, J. (1984). Self-Handicapping among Competitive Athletes: The Role of Practice in Self-Esteem Protection. Basic and Applied Social Psychology, 5, 197-209. https://doi.org/10.1207/s15324834basp0503_3

Ross, S. R., Canada, K. E., \& Rausch, M. K. (2002). Self-Handicapping and the Five Factor Model of Personality: Mediation between Neuroticism and Conscientiousness. Personality and Individual Differences, 32, 1173-1184. https://doi.org/10.1016/S0191-8869(01)00079-4

Russell, D. W., Kahn, J. H., Spoth, R., \& Altmaier, E. M. (1998). Analyzing Data from Experimental Studies: A Latent Variable Structural Equation Modeling Approach. Journal of Counseling Psychology, 45, 18-29. https://doi.org/10.1037/0022-0167.45.1.18

Sahranç, Ü. (2011). An Investigation of the Relationships between Self-Handicapping and Depression, Anxiety, and Stress. International Online Journal of Educational Sciences, 3, 526-540.

Schöllgen, I., Huxhold, O., Schüz, B., \& Tesch-Römer, C. (2011). Resources for Health: Differential Effects of Optimistic Self-Beliefs and Social Support According to Socioeconomic Status. Health Psychology, 30, 326-335. https://doi.org/10.1037/a0022514

Schreuder, J. A., Roelen, C. A., Groothoff, J. W., van der Klink, J. J., Magerøy, N., Pallesen, S., Bjorvatn, B., \& Moen, B. E. (2012). Coping Styles Relate to Health and Work Environment of Norwegian and Dutch Hospital Nurses: A Comparative Study. Nursing Outlook, 60, 37-43. https://doi.org/10.1016/j.outlook.2011.05.005

Showers, C., \& Ruben, C. (1990). Distinguishing Reflectivity from Depression: Negative Expectations and Positive Coping Mechanisms. Cognitive Therapy and Research, 14, 385-399. https://doi.org/10.1007/BF01172934

Smith, L., Sinclair, K. E., \& Chapman, E. S. (2002). Students' Goals, Self-Efficacy, Self-Handicapping, and Negative Affective Responses: An Australian Senior School Student Study. Contemporary Educational Psychology, 27, 471-485. https://doi.org/10.1006/ceps.2001.1105

Urdan, T., \& Midgley, C. (2001). Academic Self-Handicapping: What We Know, What More There Is to Learn. Educational Psychology Review, 13, 115-138.

https://doi.org/10.1023/A:1009061303214 
Vollrath, M. E., \& Torgersen, S. (2008). Personality Types and Risky Health Behaviors in Norwegian Students. Scandinavian Journal of Psychology, 49, 287-292. https://doi.org/10.1111/j.1467-9450.2008.00631.x

Wang, W., \& Miao, D. (2009). The Relationships among Coping Styles, Personality Traits and Mental Health of Chinese Medical Students. Social Behavior and Personality, 37, 163-172. https://doi.org/10.2224/sbp.2009.37.2.163

Wei, M. H., \& Lu, C. M. (2005). Development of the Short-Form Chinese Health Promoting Lifestyle Profile. Journal of Health Education, 24, 25-46.

Zuckerman, M., \& Tsai, F. F. (2005). Costs of Self-Handicapping. Journal of Personality, 73, 411-442. https://doi.org/10.1111/j.1467-6494.2005.00314.x

Zuckerman, M., Kieffer, S. C., \& Knee, C. R. (1998). Consequences of Self-Handicapping: Effects on Coping, Academic Performance, and Adjustment. Journal of Personality and Social Psychology, 74, 1619-1628. https://doi.org/10.1037/0022-3514.74.6.1619 